\title{
Triple-Negative Breast Cancer Clinicopathology: A Single-Center Experience
}

\author{
Dedy Hermansyah ${ }^{1 *}$, Yolanda Rahayu ${ }^{2}$, Arjumardi Azrah ${ }^{2}$, Gracia Pricilia $^{2}$, Sufida ${ }^{3}$, \\ Denny Rifsal ${ }^{1}$, Albiner Simarmata ${ }^{4}$ \\ ${ }^{1}$ Department of Surgery, Oncology Division, Faculty of Medicine, University of North Sumatera, Medan, Indonesia \\ ${ }^{2}$ Department of Surgery, Faculty of Medicine University of North Sumatera, Medan, Indonesia \\ ${ }^{3}$ Department of Anatomical Pathology, Murni Teguh Memorial Hospital, Medan, Indonesia \\ ${ }^{4}$ Department of Surgery, Oncology Division, Pirngadi Regional General Hospital, Medan, Indonesia
}

\section{ARTICLE INFO}

Received : 03 October 2020

Reviewed : 01 November 2020

Accepted : 19 Febuary 2021

Keywords:

clinicopathology, triple-negative

breast cancer

\begin{abstract}
A BSTRACT
Background: Triple-negative breast cancer (TNBC) is a subtype of breast cancer that does not have estrogen receptors, progesterone receptors, and HER-2 receptors. This subtype is found in $15-20 \%$ of all types of breast cancer, and it is often associated with a high recurrence rate and mortality after getting definitive therapy. The aim of our study is to investigate the clinicopathology of breast cancer in our center, where the majority were Bataknese.
\end{abstract}

Methods: We evaluated the clinical and pathological characteristics of TNBC retrospectively from medical records data, from January 2017 to December 2019 with a total of 105 patients but only 79 patients had complete clinicopathological and immunohistochemistry data. This study was conducted in Murni Teguh Memorial Hospital, Medan, Indonesia.

Results: From 79 TNBC patients, the average age at clinical presentation was $41-50$ years group about 35 samples (44.3\%). All patients had an invasive type of ductal carcinoma (100\%). The majority of tumor size was T2 in 51 patients $(64,6 \%), 83.6 \%$ grade 3 tumors. Both angioinvasion and lymph invasion were found in 48 patients $(60.8 \%)$ while tumor-infiltrating lymphocyte (TIL) was found in 58 patients $(73.4 \%)$, and 44 patients $(55.7 \%)$ had lymph node metastases.

Conclusions: According to some existing literature, TNBC showed more aggressive characteristics which are the same as our study. TNBC was diagnosed at young age, grade 3 tumors, having TIL which is very likely to occur distant metastases to lymph nodes.

\section{INTRODUCTION}

Triple-negative breast cancer (TNBC) is defined as the absence of estrogen, progesterone, and HER-2 receptors obtained from immunohistochemical examination [1,2]. This type is often considered a subtype that has aggressive tumor biology with high recurrence and mortality rates. Most of the TNBC cases demonstrated high grading, angioinvasion, lymph invasion, and high tumor-infiltrating lymphocyte (TIL) which made it different from other types of breast cancer [3].

TNBC incidence in the Western Countries is at 12.2$13 \%$ of all breast cancers [4]. The latest epidemiologic study in the Asian population showed that breast cancer cases in Indonesia were reported to be 49,998 cases in 2017, in which theoretically $15-25 \%$ of them were triple-negative subtype. Based on Aziz et al. [5] study in Malaysia, the mean age of TNBC patients at diagnosis was 48 years. Similarly, two previous studies on TNBC patients in Malaysia showed that the mean age of TNBC patients at diagnosis was 48.0 and 53.3 years. TNBC displays a significant racial disparity in the incidence and outcomes [6,7]. For example, African American women have a higher incidence risk for TNBC and have a worse 5-year survival rate than Caucasian women with TNBC $[1,8,9]$.

Several studies have demonstrated that patients with triple-negative breast cancer or basal-like breast cancer have a worse prognosis than other molecular subtypes. Negative triple breast cancer has progression-free survival (PFS) and poor overall survival (OS). The risk 
of long-term recurrence at 5 years was higher in patients with TNBC compared to other subtypes. The high invasive nature of TNBC suggests higher risks of metastasis and local recurrence of TNBC. Studies reported that the frequency of recurrence or metastasis was higher in TNBC as compared to non-TNBC patients $[4,6,7,9]$. This study was performed to examine the clinicopathological features of TNBC the majority of which in our center were Bataknese.

\section{METHODS}

This is a descriptive study that evaluated the clinical and pathological characteristics of TNBC retrospectively, from January 2017 to December 2019 in Murni Teguh Memorial Hospital, Medan, Indonesia. Data were taken from medical records about clinicopathological features and complete immunohistochemistry data from breast cancer patients. We found 105 TNBC patients, but only 79 patients had complete data of the clinicopathology and immunohistochemistry.

In this study, we did not analyze our primary data but only presented descriptive data of our patient's clinicopathological features using SPSS ver 22.

\section{RESULTS}

Table 1 shows the frequency distribution based on age group, size, histology, grade, lymph invasion, TIL, angio invasion, and lymph node metastasis as follows.

Out of the 79 patients, the average age at clinical presentation was $41-50$ years group with 35 samples (44.3\%). The largest tumor size was in T2 as many as 51 patients, $100 \%$ invasive ductal carcinoma, of which $83.6 \%$ were grade 3 . Angioinvasion was found in $60.8 \%$ while $60.8 \%$ was lymph invasion. TIL is an indicator of cell proliferation. It was found that $73.4 \%$ of TNBC had Intermediate and High TIL. Lymph node metastasis was found in $55.7 \%$ of cases.

\section{DISCUSSION}

The results of our study with the samples who are mostly Bataknese in Medan, Indonesia, are not much different from the results of previous studies [9].

In this study, the mean age of TNBC patients was 50 years. A 2016 study comparing TNBC with and without lymph node metastases found a median age of 49.5 and 50.0 years, respectively. The age range in TNBC also varies. Nurwenda et al. [10] found the age range of TNBC patients with and without lymph node metastasis was $37-70$ and $27-74$ years. Rayson et al. [1] conducted a prospective analysis of 412 TNBC patients who found nearly half of the population seen with patients over 60 years of age. Rayson's study aimed to
Table 1. Clinical and histopathological features of patients with TNBC

\begin{tabular}{|c|c|c|c|}
\hline Parameter & & $N=79$ & $\begin{array}{l}\text { Percentage } \\
\text { (\%) }\end{array}$ \\
\hline \multirow[t]{5}{*}{ Age } & $<30$ & 4 & $5.1 \%$ \\
\hline & $31-40$ & 27 & $34.1 \%$ \\
\hline & $41-50$ & 35 & $44.3 \%$ \\
\hline & $51-60$ & 10 & $12.7 \%$ \\
\hline & $>60$ & 3 & $3.8 \%$ \\
\hline \multirow[t]{3}{*}{ Size } & $\mathrm{T} 1$ & 8 & $10.1 \%$ \\
\hline & $\mathrm{T} 2$ & 51 & $64.6 \%$ \\
\hline & T3 & 20 & $25.3 \%$ \\
\hline \multirow[t]{2}{*}{ Histology } & IDC & 79 & $100 \%$ \\
\hline & Other Type & 0 & $0 \%$ \\
\hline \multirow[t]{3}{*}{ Grade } & 1 & 0 & $0 \%$ \\
\hline & 2 & 13 & $16.4 \%$ \\
\hline & 3 & 66 & $83.6 \%$ \\
\hline \multirow[t]{2}{*}{ Lymph invasion } & Yes & 48 & $60.8 \%$ \\
\hline & No & 31 & $39.2 \%$ \\
\hline \multirow{3}{*}{$\begin{array}{l}\text { Tumor-infiltrating } \\
\text { lymphocyte }\end{array}$} & Low & 21 & $26.6 \%$ \\
\hline & Intermediate & 44 & $55.7 \%$ \\
\hline & High & 14 & $17.7 \%$ \\
\hline \multirow[t]{2}{*}{ Angio invasion } & Yes & 48 & $60.8 \%$ \\
\hline & No & 31 & $39.2 \%$ \\
\hline \multirow{2}{*}{$\begin{array}{l}\text { Lymph node } \\
\text { metastases }\end{array}$} & Yes & 44 & $55.7 \%$ \\
\hline & No & 35 & $44.3 \%$ \\
\hline
\end{tabular}

assess the relationship between age and prognosis of TNBC patients with the result that there was no significant difference in prognosis in the age group of fewer than 60 years and more than 60 years. However, patients with TNBC at a young age were found to receive more chemotherapy than older age groups. There were no significant differences in tumor characteristics such as size, histological grade, and involvement of lymph nodes $[1,11,12]$. Another study found the median age was 41 years with a range of 22-61 years [13].

Tumor size in this study was found in 51 of a total of 79 patients with a size of $20-50 \mathrm{~mm}$ (T2). Chen conducted a study on tumor size and lymph node metastases, obtaining a TNBC tumor size $>2 \mathrm{~cm}$ by $54.5 \%$ in patients without lymph node metastases and 75.9\% with lymph node metastases which were statistically significant $[13,14]$.

In this study, all patients with histopathological types of invasive ductal carcinoma were found. In another study, $76.7 \%$ of TNBC were found with histopathology of invasive ductal carcinoma [15]. A study on TNBC and lymph node metastases found that histopathological 
types of patients with and without axillary lymph node metastases were mostly associated with the histopathological type of invasive ductal carcinoma, $85.7 \%$, and $89.2 \%$, respectively [10].

Nurwenda et al. [10] obtained the results of TNBC histology grade with and without lymph node metastasis, most of which were grade III (89.3\% and $82.1 \%)$. Dewi et al. [15] research on 30 samples obtained histological grade III of only $66.7 \%$, but for tumor size in that study, there were more tumors with a size of $>50 \mathrm{~mm}$ (72.7\%).

In this study, $60.8 \%$ angioinvasion was obtained. The angioinvasion process in TNBC is influenced by changes in genes in TNBC. There are molecular differences between TNBC with a low histological grade and TNBC with a high histological grade which will later affect the specific chromosome translocation which affects the fusion process of the gene complex. In TNBC, vasculogenesis activity is found which resembles the rapid vasculogenesis process in the embryo. There is the formation of lacunae surrounded by tumor cells, which is a sign of poor prognosis of TNBC $[12,13]$. An examination using microvascular density (MVD) to assess angiogenesis revealed an increase in microvascular density associated with tumor size, histological grade of lymph node metastases, and poor prognosis [8].

Lymphovascular invasion in our study was found to be $60.8 \%$. A cross-sectional study with a sample size of 2017 patients found only $22.7 \%$ of TNBC patients out of a total of 88 patients experienced lymphovascular invasion $[13,14]$. Lymphovascular invasion of the peritumoral affects the prognosis and adversely affects the survival and recurrence of TNBC [16]. TNBC, according to the literature, is present in $10-20 \%$ with the characteristics of early metastasis, chemotherapy resistance, and poor survival. However, there is a paradoxical term TNBC which shows a good response to neoadjuvant chemotherapy but has the worst average survival compared to other subtipemolecular types [17].

In this study, TIL was found with an intermediate and high risk of $73.4 \%$. TIL was found to increase tumor proliferation associated with high histologic grade, high Ki67, larger tumor size, and lymph node metastases. Some researchers get TIL with a high risk of TNBC [17]. However, Li et al. [18] found $69.41 \%$ of TNBC patients with low TIL scores (< 10\%).

In this study, lymph node metastasis was found at $55.7 \%$. A study with a total of 398 patients with earlystage TNBC found $91.4 \%$ with invasive ductal histological characteristics with a grade III histology of $86.9 \%$; only $21.4 \%$ of lymph node metastases were found $[17,18]$. A study in Korea that assessed the prognosis of TNBC patients obtained $49.4 \%$ lymphoma metastases, which influenced the choice of axillary dissection procedure [4].

Triple-negative breast tumor has shown to have aggressive behavior due to widespread lymphovascular invasion and distant metastasis. Because this was a descriptive study, we did not analyze the variable. Future study is needed to analyze all the histopathological parameters.

\section{CONCLUSIONS}

In accordance with some existing literature, our TNBC shows more aggressive characteristics. In our study, TNBC was diagnosed at a young age, grade 3 tumor, having TIL which is very likely to occur distant metastasis to lymph nodes.

\section{DECLARATIONS}

\section{Competing of Interest}

The authors declare no competing interest in this study.

\section{Ethics Approval}

This study has been approved by the Ethics Committee of the Murni Teguh with the ethical clearance no. 654/ SP/MTMH/X/2020.

\section{Acknowledgment}

The authors would like to express the deepest gratitude to our colleagues and technicians from the University of North Sumatera and Murni Teguh Memorial Hospital who provided insight and expertise that assisted the research.

\section{REFERENCES}

1. Rayson D, Payne JI, Michael JC, et al. The impact of detection method and age on survival outcomes in triple-negative breast cancer: a population based cohort analysis. Clin Breast Cancer. 2018;18(5):e955e960.

2. Gowry MR, Pooja KS, Radha RP. Clinicopathological features of triple negative breast carcinoma. J Clin Diagn Res. 2017;11(1):EC05-EC08.

3. Radosa CJ, Eaton A, Stempel M, et al. Evaluation of local and distant recurrence patterns in patients with triple-negative breast cancer according to age. Ann Surg Oncol. 2017;24(3):698-704.

4. Jeanny K, Keun-Yong E, Tae RK, et al. A prognostic model for patients with triple-negative breast cancer: importance of the modified nottingham prognostic index and age. J Breast Cancer. 2017;20(1):65-73.

5. Abdul Aziz AA, Md Salleh MS, Ankathil R. Clinicopathological and prognostic characteristics of Malaysian triple negative breast cancer patients undergoing TAC chemotherapy regimen. Int J Breast Cancer. 2020;2020:8424365.

6. Aishwarya K, Antoinette MS, Lisa EP, et al. Breast cancer Incidence and mortality by molecular subtype: statewide age and racial/ethnic disparities in New Jersey. Cancer Health Disparities. 2019;3:e1-e17. 
7. Gulbahce HE, Bernard PS, Weltzien EK, et al. Differences in molecular features of triple negative breast cancers based on age at diagnosis. Cancer. 2018;124(24):4676-84.

8. Medina MA, Oza G, Sharma A, et al. Triple-negative breast cancer: a review of conventional and advanced therapeutic strategies. Int J Environ Res Public Health. 2020;17(6):2078.

9. Widodo I, Dwianingsih EK, Aryandono T, Soeripto S. Clinicopathological characteristic and prognostic significance of Indonesian triple negative breast cancer. Indones Biomed J. 2019;11(3):225-337.

10. Nurwenda S, Dewayani BM, Afiati A, Hernowo BS. Ekspresi negatif melanoma cell adhesion molecule (mcam) berkorelasi dengan metastasis kelenjar getah bening aksila pada triple negative breast cancer. Indones J Clin Pharm. 2016;5(3).

11. DiNome M, Javier IJ, Matsuba C, et al. Clinicopathological features of triple-negative breast cancer epigenetic subtypes. Ann Surg Oncol. 2019;26(10):3344-53.

12. Wahba HA, El-Hadaad HA. Current approaches in treatment of triplenegative breast cancer. Cancer Biol Med. 2015;12:106-16.
13. Lehmann BD, Jovanović B, Chen X, et al. Refinement of triple-negative breast cancer molecular subtypes: implications for neoadjuvant chemotherapy selection. PLoS One. 2016;11(6): e0157368.

14. Rui J, Xiaochi H, Jingtao L. Clinical characteristics and prognostic analysis of ipsilateral supraclavicular lymph node metastases in breast cancer patients: a retrospective study. Int J Clin Exp Pathol. 2019;12(9):3526-34.

15. Dewi C, Sulastri H, Fantoni J, Hafy Z. Hubungan ekpresi e-cadherin dengan invasi limfovaskular dan status KGB pada karsinoma payudara tripel negatif. Patologi. 2013; 22(1):10-16.

16. Hwang SY, Park, S, Kwon, Y. Recent therapeutic trends and promising targets in triple negative breast cancer. Pharmacol Ther. 2019;199:30-57.

17. Walsh EM, Keane MM, Wink DA, et al. A review of triple negative breast cancer (TNBC) and the impact of inducible nitric oxide synthase on TNBC tumour biology and patient outcomes. Crit Rev Oncog. 2016;21(5-6):333-51.

18. Li X, Yang J, Peng L, et al. Triplenegative breast cancer has worse overall survival and cause-specific survival than non-triple-negative breast cancer. Breast Cancer Res Treat. 2017;161:279-87. 